\title{
The Cost-Effectiveness of Lorlatinib Versus Chemotherapy as a Second- or Third-Line Treatment in Anaplastic Lymphoma Kinase (ALK)-Positive Non-small-cell Lung Cancer in Sweden
}

\author{
Fredrik O. L. Nilsson ${ }^{1,4}$ (I) Sandra T. Asanin ${ }^{1} \cdot$ Elizabeth T. Masters $^{2} \cdot$ Laura ladeluca $^{2} \cdot$ Chrissy Almond $^{3}$. \\ Miranda Cooper ${ }^{3} \cdot$ Sarah Smith ${ }^{3}$
}

Accepted: 6 March 2021 / Published online: 3 June 2021

(c) The Author(s) 2021

\begin{abstract}
Background Lorlatinib is a third-generation anaplastic lymphoma kinase (ALK)/c-ros oncogene 1 (ROS1) tyrosine kinase inhibitor (TKI) with efficacy in patients with $A L K$-rearranged non-small-cell lung cancer (NSCLC) previously treated with a second-generation ALK inhibitor or with first- and second-generation ALK inhibitors. We examined the cost-effectiveness of second- or third-line+ (2L+or 3L+) lorlatinib in Sweden, versus chemotherapy.

Methods A partitioned survival model with three health states (progression free, progressed, or death) was used. Lorlatinib relative efficacy versus chemotherapy was derived using unanchored matching adjusted indirect treatment comparisons from a phase 2 clinical trial. Utility data were derived from the same trial and published studies. Costs (year 2019) were obtained from Swedish national data. Costs and benefits were discounted at 3\% per annum using a societal perspective (base case). Model robustness was evaluated with deterministic and probabilistic sensitivity analyses.

Results For 2L+, the average discounted total quality-adjusted life year (QALY) gain was 1.29 years. Total incremental costs were Swedish krona (SEK) 731,791, resulting in an incremental cost-effectiveness ratio (ICER) of SEK 566,278 per QALY gained. Non-discounted survival gain amounted to 1.94 years. For 3L+, the average discounted total QALY gain was 1.25 years. Total incremental costs were SEK 754,801, resulting in an ICER of SEK 603,934 per QALY gained. Nondiscounted survival gain was 1.88 years. Sensitivity analyses were consistent.

Conclusions ICERs ranged from SEK 421,000 to SEK 384,066 less than the boundary for a cost-effective treatment for a high-severity disease in Sweden (SEK 988,000), suggesting 2L+ or 3L+ lorlatinib is a cost-effective treatment for $A L K$ positive NSCLC versus chemotherapy.
\end{abstract}

\section{Introduction}

Lung cancer causes the highest number of cancer-related deaths worldwide [1]. Resistance to therapy is a major clinical issue contributing to poor prognosis [2]. Non-small-cell lung cancer (NSCLC) accounts for approximately $80-85 \%$ of all lung cancers [3, 4]. In 2016, Sweden recorded 4108 new lung cancer cases; 3677 patients died from the disease in that year $[5,6]$.

Fredrik O. L. Nilsson

Fredrik.Nilsson@pfizer.com

Pfizer Innovations AB, Stockholm, Sweden

Pfizer Inc., New York, NY, USA

BresMed, Sheffield, UK

4 Vetenskapsvägen 10 SE-191 90, Sollentuna, Sweden
Treatment of advanced/metastatic NSCLC has traditionally involved chemotherapy, with poor 5-year survival rates, although targeted therapy has become a primary treatment modality in subgroups of NSCLC [2, 7]. Genetically altered rearrangements in the receptor tyrosine kinase anaplastic lymphoma kinase $(A L K)$ affect $2-7 \%$ of patients with NSCLC [8-10]. Crizotinib is a first-generation ALK tyrosine kinase inhibitor (TKI), the first to be approved, followed by the second-generation ALK inhibitors (ceritinib, alectinib, brigatinib) [8]. With multiple ALK inhibitors available, treatment consists of sequential administration of different generation TKIs followed by chemotherapy at disease progression [11]. However, many patients develop resistance to their initial and subsequent ALK-TKIs [12-14].

Swedish guidelines for $A L K$-positive NSCLC are consistent with those from the European Society for Medical Oncology (ESMO) [6, 7]. Patients with $A L K$ rearrangements 


\section{Key Points for Decision Makers}

Our analysis, based on an unanchored matching adjusted indirect comparison, suggests second- or third-line treatment with lorlatinib is likely to be a cost-effective option for patients affected by anaplastic lymphoma kinase $(A L K)$-positive non-small-cell lung cancer.

Treating with lorlatinib instead of chemotherapy leads to substantial gains in quality-adjusted life years.

The results are robust but the cost-effectiveness of lorlatinib is most sensitive to the relative efficacy of lorlatinib versus chemotherapy for overall and progression-free survival.

should initially be offered treatment with one of four approved ALK TKIs: alectinib, brigatinib, crizotinib, or ceritinib. Patients who experience tumour progression during treatment with crizotinib should be switched to alectinib, brigatinib, or ceritinib. Following treatment failure on any of the second-generation agents, the recommended option is lorlatinib. Once all targeted options are exhausted, platinum-based combination chemotherapy should be considered. [15].

Lorlatinib is a potent third-generation ALK/c-ros oncogene 1 (ROS1) TKI with proven efficacy in patients with $A L K$-rearranged NSCLC following previous treatment with a second-generation ALK inhibitor or with first- and secondgeneration ALK inhibitors [16, 17]. It received conditional approval in the European Union in May 2019 as monotherapy for the treatment of adults with $A L K$-positive advanced NSCLC whose disease has progressed after alectinib or ceritinib as the first ALK TKI therapy or crizotinib and at least one other ALK TKI $[18,19]$. Lorlatinib is therefore used in a treatment setting where chemotherapy is the only alternative treatment and patients typically experience poor outcomes $[17,18]$. The objective of this study was to examine the cost-effectiveness of lorlatinib as second- or third-line treatment in Sweden, compared with chemotherapy, its relevant comparator in this treatment setting.

\section{Methods}

\subsection{Model Structure}

The model was created in Microsoft Excel and structured as a partitioned survival model (PSM) (Fig. 1), a common modelling structure in oncology and an approach consistent with previous submissions to the National Institute for

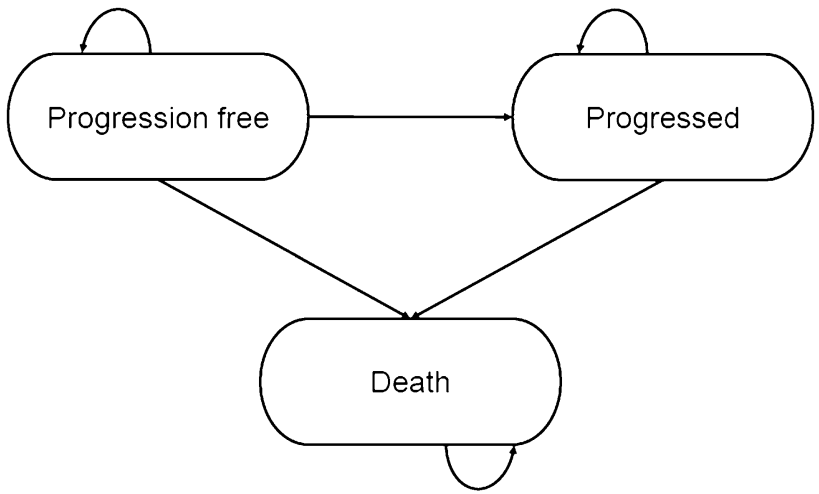

Fig. 1 Partitioned survival model structure. All patients enter the model and initiate therapy as progression free; treatment is assumed to continue until the disease progresses or the patient dies

Health and Care Excellence (NICE) and Tandvårds- och läkemedelsförmånsverket (TLV) for $A L K$-positive NSCLC. A recent systematic review found that PSMs were the most widely used approach for cost-effectiveness analyses of licensed drugs for previously treated epidermal growth factor receptor $(E G F R)$ - and $A L K$-negative advanced/metastatic NSCLC [20]. Despite this, the NICE Decision Support Unit [21] has recommended that state transition models should be used alongside PSMs to address uncertainties in the extrapolation period due to the explicit modelling of the health state occupancy in that type of model. However, due to the very high mortality rate of the $A L K$-positive patient population and the hazard ratio (HR) approach used to model relative survival, using the alternative modelling method and adjusting survival probabilities in the extrapolation period would only have had a marginal impact on results. Since duplet modelling is highly resource intensive, the decision was made to focus on the PSM.

In this method, the area under each survival curve (progression-free survival [PFS] and overall survival [OS]) defines the proportion of patients that are progression free (PF), have progressed disease (PD), or are dead, and is used to allocate patients to each of those health states at each time point. All patients enter the model and initiate therapy as $\mathrm{PF}$, and treatment is assumed to continue until the disease progresses or the patient dies. Within the PF state, it is assumed that a patient's disease is in a stable or responding state and not actively progressing. Progression was defined in the model as it was in the lorlatinib phase $1 / 2$ trial [17, 22], using the Response Evaluation Criteria in Solid Tumors (RECIST). Patients in the PF state are assumed to incur costs associated with treatment, including drug costs for lorlatinib or chemotherapy, costs of drug administration during PF disease, and costs associated with medical management of the condition and the management of grade $3 / 4$ adverse events (AEs). Patients also experience a higher utility weighting 
when compared with PD, as their tumour and related symptoms are controlled.

Patients who experience disease progression (as defined by RECIST) will transition into the PD health state. In this state, the patient will move on to subsequent treatment lines (if appropriate) before death. Patients may continue to incur costs associated with medical management and experience a lower utility weighting than in the PF state. Post-progression treatment contributes only to costs and does not change the OS beyond the trial outcomes. The efficacy of later treatment lines is assumed to be captured by the survival curves extrapolated from the clinical studies [22-24]. Treatment waning was not applied, as using treatment waning within reasonable bounds would have a negligible impact on results for this patient population due to a very high mortality rate.

Since each health state is associated with specific treatment costs and quality-of-life levels, it is possible to calculate the estimated total treatment costs over the patients' remaining life span, and total gained quality-adjusted life years (QALYs) and life years (LYs). The cycle length in the base-case model is 30 days. A half-cycle correction (i.e. averaging outcomes between the beginning and end of each cycle to reflect that events can occur at any point within the cycle) is applied to all costs and outcomes except for drug costs (which are incurred at the beginning of each cycle). The base-case time horizon is 20 years, i.e. a lifetime perspective for these patients since fewer than one in 1000 patients are alive at that time point according to our modelling, to ensure all relevant clinical and economic outcomes that occur within the patient cohort in the economic model are captured. The base-case analysis uses the societal perspective in line with current Swedish health technology assessment guidance [25]. The outcomes are measured in LYs gained, PF-LYs gained, QALYs gained, and total costs. The incremental cost-effectiveness ratio (ICER) is then calculated. Analyses were based on 2019 costs [26], and costs and benefits were discounted at $3 \%$ per annum (in accordance with TLV guidance [27]). The ICERs were evaluated in the context of what is normally considered to be an acceptable threshold for a high-severity disease in Sweden (Swedish krona [SEK] 988,000) [28].

\subsection{Patient Population}

The design, efficacy, and safety details from the phase 2 portion of the phase $1 / 2$ study used to inform this model have been described in detail previously [17, 22]. Briefly, this was a multicenter, open-label, single-arm, phase 1/2 study (ClinicalTrials.gov identifier: NCT01970865) designed to assess the antitumour activity and safety of lorlatinib in patients with $A L K$-positive or ROS1-positive advanced NSCLC.

In phase 2, eligible patients, who had histologically or cytologically confirmed metastatic NSCLC carrying an $A L K$ or ROS1 rearrangement (with or without asymptomatic untreated or treated central nervous system metastases), were enrolled into several $A L K$-positive expansion cohorts (EXP) and one ROS1-positive cohort (Table 1). Our model uses data from cohorts EXP3B, EXP4, and EXP5 (EXP3B-5; patients with $A L K$-positive advanced NSCLC who had been previously treated with at least one other ALK TKI other than crizotinib). This is defined as the second-line+ $(2 \mathrm{~L}+)$ cohort in the model. An alternative treatment cohort (thirdline $+[3 \mathrm{~L}+])$ is also defined in the model, which excludes EXP3B and includes only patients who have been previously treated with at least two ALK TKIs.

\subsection{Model Inputs}

\subsubsection{Efficacy Data}

Efficacy data (OS and PFS based on independent central review) for lorlatinib were taken from the phase 2 trial for the $2 \mathrm{~L}+$ and $3 \mathrm{~L}+$ cohorts [17]. Parametric survival models (Weibull, log-normal, log-logistic, exponential, generalised

Table 1 Phase 2 study expansion cohorts

\begin{tabular}{ll}
\hline Cohort & Patients \\
\hline EXP1 & $\begin{array}{c}\text { Treatment-naïve patients with advanced } A L K \text {-positive NSCLC } \\
\text { EXP2 }\end{array}$ \\
$\begin{array}{c}\text { Patients with advanced } A L K \text {-positive NSCLC previously treated with crizotinib therapy, without prior chemotherapy in the } \\
\text { metastatic setting }\end{array}$ \\
EXP3A & $\begin{array}{c}\text { Patients with advanced } A L K \text {-positive NSCLC relapsing after crizotinib with prior chemotherapy in the metastatic setting } \\
\text { EXP3B }\end{array}$ \\
$\begin{array}{c}\text { Patients with advanced } A L K \text {-positive NSCLC relapsing after one ALK inhibitor therapy other than crizotinib with or without any } \\
\text { number of prior chemotherapy regimens in any disease setting }\end{array}$ \\
EXP4 & $\begin{array}{c}\text { Patients with advanced } A L K \text {-positive NSCLC relapsing after two prior lines of ALK inhibitor therapies. Patients were permitted to } \\
\text { have any number of prior chemotherapy regimens in any disease setting }\end{array}$ \\
EXP5 & $\begin{array}{c}\text { Patients with advanced } A L K \text {-positive NSCLC relapsing after three prior lines of ALK inhibitor therapies. Patients were permitted to } \\
\text { have any number of prior chemotherapy regimens in any disease setting }\end{array}$ \\
EXP6 & Patients with advanced $R O S 1$-positive NSCLC who were treatment-naïve or who had any number of prior cancer therapies
\end{tabular}

$A L K$ anaplastic lymphoma kinase, EXP expansion cohort, NSCLC non-small-cell lung cancer, ROS1 c-ros oncogene 1 
gamma, and Gompertz distributions) were fitted to the observed OS and PFS data for each of the relevant populations, the $2 \mathrm{~L}+$ cohort and $3 \mathrm{~L}+$ cohort, and then extrapolated over the time horizon. Following visual inspection and statistical testing (Akaike information criterion, Bayesian information criterion) for the $2 \mathrm{~L}+/ 3 \mathrm{~L}+$ cohorts, the parametric distribution selected for PFS was the generalised gamma distribution and for OS was the exponential distribution. These distributions were selected for the base-case model as they had the best statistical fit and reasonable visual fit (Supplement 1, see the electronic supplementary material). The use of an exponential distribution for OS is in line with the approach used by TLV in its evaluation of alectinib, but likely results in a conservative OS estimate. The recommendations by Latimer [29] were used, but in the absence of long-term data for lorlatinib, sensitivity analyses with the most conservative and optimistic extrapolations were also performed.

Since there are no head-to-head studies comparing lorlatinib with chemotherapy, and lorlatinib was investigated in a single-arm trial, the relative efficacy of lorlatinib compared with chemotherapy treatment was estimated using unanchored matching adjusted indirect comparisons (MAICs) (full details in Supplement 1, see the electronic supplementary material) [30, 31]. Relevant PFS data for chemotherapy (either pemetrexed or docetaxel) were identified through a systematic literature review (SLR) (full details in Supplement 1), and included the chemotherapy arms of the ALUR [23] (alectinib vs. chemotherapy) and ASCEND-5 [32] (ceritinib vs. chemotherapy) studies. For PFS, the basecase adjusted HR comparing lorlatinib and chemotherapy was calculated using aggregate data from the ALUR and ASCEND-5 studies for chemotherapy and patient-level data for lorlatinib cohorts EXP2 and EXP3A. For these cohorts, baseline demographics and disease characteristics, including prior lines of therapy, were generally consistent with the populations in the ALUR and ASCEND-5 studies. After matching, the corresponding HR was 0.224 (95\% confidence interval $[\mathrm{CI}]$ 0.154-0.312), demonstrating that lorlatinib leads to a significant reduction in the hazard of progression compared with chemotherapy. Threshold analyses for the MAIC are presented in Supplement 2 (see the electronic supplementary material). A sensitivity MAIC analysis was conducted using patient-level data for lorlatinib cohorts EXP3B-5, resulting in an HR of $0.362(95 \%$ CI $0.297-0.440$ ). In comparison with the base case, the relative treatment effect was reduced. This was expected given that the health of the patients within cohorts EXP3B, EXP4, and EXP5 was expected to be poorer. Despite this, lorlatinib was still shown to significantly reduce the hazard of progression compared with chemotherapy in this population.

No suitable OS data for chemotherapy were identified from the SLR to compare with the lorlatinib cohorts; therefore, the HRs for OS were primarily assumed to be equal to the HRs for PFS. This also aligns with the assumption taken by the NICE Evidence Review Group in the appraisal of crizotinib in ROS1-positive advanced NSCLC [33]. As an alternative, the retrospective analysis of OS data for patients on systemic therapy after progression on crizotinib, presented in Ou et al. (2014), was considered [24]. A MAIC with lorlatinib based on this study results in an OS HR of 0.159 (95\% CI 0.052-0.356) when EXP2-3A is utilised and 0.425 (95\% CI 0.274-0.601) when EXP3B-5 is utilised. However, the limitations around the comparability of this study to the lorlatinib cohorts should be considered, including the retrospective nature of the study by $\mathrm{Ou}$ et al., as should our assumption that systemic therapy is suitable to represent the outcomes for chemotherapy (although the type of chemotherapy regimen was not captured by Ou et al.), and the low number of patients receiving systemic therapy (37 patients). All MAICs conducted are limited by the strong assumption that no prognostic factors or treatment effect modifiers are in imbalance between the two populations.

The HRs calculated based on the MAICs were then applied to the OS and PFS curves for lorlatinib, specific to the selected model population ( $2 \mathrm{~L}+$ or $3 \mathrm{~L}+$ cohort), to predict outcomes for chemotherapy. This assumes that hazards are proportional between treatments and the HR, the relative treatment effect, is consistent irrespective of the number of prior treatments. In all cases, the hazard of survival was capped based on the expected survival of the general population, i.e. in no cycle had the treated population a lower mortality than the general population [34]. As time on treatment was reported differently in different studies, it could not be included directly in the MAIC; an alternative approach was therefore taken as follows: In the lorlatinib trial, patients discontinued lorlatinib treatment in the event of confirmed progression (unless in the investigator's opinion the patient was still deriving clinical benefit), intolerable AEs, or death; the model assumes time on treatment to be equal to PFS for lorlatinib; for chemotherapy, an exponential distribution was assumed based on the median time on treatment reported in trials [32].

\subsubsection{Utility Weights}

In the lorlatinib phase 2 trial, patients completed two wellestablished patient-reported outcome instruments while on lorlatinib treatment: European Organisation for Research and Treatment of Cancer (EORTC) QLQ-C30 and QLQ-LC13 [35-38]. To generate utility measures, in accordance with NICE guidance, results from the EORTC QLQ-C30 were mapped to the EuroQol-5-dimension-3-level (EQ-5D-3L) questionnaire using an algorithm published by Longworth et al. [39] using British tariff values [40]. In Sweden, the British tariff is preferred by TLV and was therefore utilised 
Table 2 Utility values for $2 \mathrm{~L}+/ 3 \mathrm{~L}+$ cohorts

\begin{tabular}{llll}
\hline Treatment arm & National tariff & 2L+cohort & 3L+ cohort \\
\hline Progression free & & & \\
Lorlatinib [40, 41, 42] & UK & 0.785 & 0.774 \\
& Sweden & 0.870 & 0.870 \\
Chemotherapy [43] & UK & 0.747 & 0.747 \\
& Sweden & 0.826 & 0.839 \\
\multicolumn{2}{l}{ Progressed disease_lorlatinib or chemotherapy } \\
Crizotinib second-line & & 0.610 & 0.610 \\
\multicolumn{2}{l}{$\begin{array}{l}\text { NICE submission [44] } \\
\text { (base case) }\end{array}$} & & \\
Sensitivity analysis [43] & & 0.460 & 0.460 \\
\hline
\end{tabular}

$2 L+$ second line+, $3 L+$ third line+, NICE National Institute for Health and Care Excellence

in the base case. For a sensitivity analysis, Swedish tariff values were used [41]. For PF disease (chemotherapy) and for PD (both treatment arms), utility values rely on data from previously published cost-effectiveness analyses [33, 43]. Details on the utility weights used in the base case can be seen in Table 2 [40-44]. Although the utility values may appear high in comparison to some other published data [45], it should be remembered that $A L K$-positive patients are relatively young and also that patients who are responding to TKI treatment do not experience many disease symptoms. The utility values are also lower than published utility values for the corresponding age group in the general Swedish population [46].

\subsubsection{Resource Use and Costs}

Medical resource use and treatment costs estimated in the model were grouped into six categories:

Drug cost: The total drug acquisition cost was based on the calculated cycle treatment cost applied in each cycle to those remaining on treatment. The recommended dosage of lorlatinib is $100 \mathrm{mg}$ once daily. The list price for one pack containing 30 tablets with $100 \mathrm{mg}$ each was SEK 50,458.70 (retail pharmacy selling price) and SEK 67,282.85 for one pack containing 120 tablets with $25 \mathrm{mg}$ each [47]. The price was semi-flat, meaning that the daily treatment cost was the same for patients treated with $100 \mathrm{mg}$ as it was for patients treated with $75 \mathrm{mg}$, i.e. SEK 1681.96. Standard chemotherapy in this treatment setting in Sweden is pemetrexed, which was assumed to be combined with either carboplatin or cisplatin. In the base case, the respective shares were taken from the PROFILE 1014 study, where $46.2 \%$ received carboplatin and the remainder cisplatin [48]. The monthly (30-day) treatment cost for pemetrexed was SEK 34,363 and was calculated as the cheapest vial combination available in Sweden based on the patients' body surface area taken from the lorlatinib phase $1 / 2$ trial $[17,22]$. Wastage was included to allow for the fact that any unused vials will be disposed of and not reused with another patient. Relative dose intensity (RDI), adjusting for dose adjustment and treatment breaks, was applied for lorlatinib and pemetrexed in order to better reflect real-world clinical practice. The costs for administration of chemotherapy were obtained from Swedish national cost data. Treatment administration for cisplatin (with pemetrexed) is considered to be relatively resource intense and cost SEK 6758, whereas the other chemotherapies are considered to be less complicated and cost SEK 6094 [49].

$A E$ costs: Treatment-emergent AE costs were included based on the impact of treatment-emergent AEs grade 3 or higher as reported in the lorlatinib [17], ALUR [23], and ASCEND-5 studies [32]. AE costs were applied in the first treatment cycle and taken from national data [50]. All AEs were assumed to be handled in an outpatient setting and most were resolved by consulting a general practitioner. As severe AEs were not common, the average AE costs were limited to SEK 543 for lorlatinib and to SEK 814 for pemetrexed. Costs relating to specific AEs are presented in Supplement 3 (see the electronic supplementary material).

Subsequent therapy cost: Fifty per cent of the patients who progressed were assumed to move on to subsequent treatment with chemotherapy (pemetrexed); the remaining $50 \%$ were assumed to be too weak to continue with chemotherapy so did not have chemotherapy-associated costs but still had the other 'disease management and monitoring costs' described in the next category. The maximum proportion of patients receiving the cost of subsequent treatments in each cycle is estimated in the model as the proportion of patients who transition from PF to PD without dying. This is estimated using the proportion of progression events which were not deaths from the lorlatinib clinical trial $(90.7 \%)$ and letting this proportion proceed to potential subsequent treatments. This probability is assumed to be constant over time, and it is assumed that this can be applied to both treatment arms.

Disease management and monitoring costs were set to differ between patients being PF and having PD but were assumed to be the same across therapies. In the model, resource use and costs for each of the health states were based on previously accepted TLV applications for TKI treatments against $A L K$-positive NSCLC for alectinib and ceritinib [51,52] and were considered to be representative of the year 2019 costs [26]. These costs primarily relate to visits to doctors (general practitioners and specialists) and nurses in an outpatient setting, but also to costs for computerised tomography scans, $\mathrm{x}$-rays, and radiotherapy. Using the values from these applications, the cycle costs for medical resource for patients being PF was SEK 1629, increasing to SEK 3325 per cycle in PD [51, 52].

Terminal care costs were applied as a one-off cost when a death event occurs. For terminal care costs that arise at the 
final stages of life, the list unit price for palliative care on a daily basis of SEK 7890/day was used [50]. In the analysis and in line with previous TLV applications, 10 days of palliative care for end-of-life treatment was assumed, i.e. a total cost of SEK 78,900.

Indirect costs: A chart review of $A L K$-positive patients with NSCLC treated with crizotinib showed that patients on average worked $8 \%$ of full-time hours while receiving second-line treatment (Pfizer, data on file). Conservatively, indirect costs are calculated on the assumption that PF patients work, on average, 2 days per cycle, which equates to a productivity value of SEK 2912 per cycle while PF (using the average monthly salary in Sweden including compulsory employer contributions [SEK 44,289] [53, 54]), regardless of being treated with lorlatinib or pemetrexed. This could be considered a conservative assumption, since patients treated with lorlatinib are expected to have a better quality of life (Table 2) and therefore a higher work ability than patients treated with pemetrexed.

\subsection{Sensitivity Analyses}

Deterministic sensitivity analyses were conducted. These included removing the RDI adjustment; altering the parametric fit of the survival curve to use log-normal, exponential, and log-logistic distributions to model PFS and a Gompertz distribution to model OS; varying the HR of OS up to 0.5; varying combinations of PFS and OS HRs; and calculating utility weights using the Swedish tariff instead of the British tariff.

Two alternative analyses were modelled based on the TLV's assessment of the data. TLV considered the 2L+ cohort to be most relevant in the Swedish setting and thus focused their analyses on that (but noted that the results were similar with the $3 \mathrm{~L}+$ cohort). The time horizon was restricted to 10 years, the perspective was narrowed to a healthcare perspective, and the utility weight post-progression was lowered to 0.460 (based on Zhou et al. 2015 [43]). The parametric distribution for PFS considered to be most appropriate was the log-normal distribution. For the OS HR, TLV acknowledged that it was reasonable to assume that it would be similar to the PFS HR. As base case, they considered the MAIC based on Ou et al. [24] and the cohort EXP3B-5 to be appropriate, with an OS HR of 0.425 . As a more conservative analysis, they applied an OS HR of 0.65 , resulting in an upper bound of the ICER.

Probabilistic sensitivity analysis (PSA) was undertaken to vary all uncertain inputs simultaneously based upon appropriate uncertainty distributions (beta distributions for parameters bounded between 0 and $1, \log$-normal distributions for HRs, multivariate normal distributions for correlated parameters such as survival curve parameters, Dirichlet distribution for multinomial distributions, and normal distributions for all other parameters). The PSA results were based on 5000 PSA iterations as this was deemed the minimum number required to produce approximately stable results.

\subsection{Validation}

Model validation was carried out in six distinctive steps:

- During model development, health economists working on the project routinely checked the internal validity and technical accuracy of the model through all stages of model development.

- The internal validity and technical accuracy of the model were also checked by an independent health economist, i.e. one that was not involved in the model development, using an extensive quality check list at first draft and prior to finalisation. Errors identified by the quality check were addressed in the final economic model.

- When the model was populated to reflect the Swedish setting, it was again reviewed independently by another health economist.

- The model was submitted in a reimbursement application to the Swedish health technology assessment agency TLV. The agency had no objections to the model structure as such, but made a few changes relating to inputs, as presented in Sect. 2.4.

- The model outcomes for PFS, OS, and post-progression survival were compared to clinical data and indicated that outcomes for the model and published estimates are broadly consistent (Supplement 4, see the electronic supplementary material).

- The Assessment of the Validation Status of Health-Economic decision models (AdViSHE) validation-assessment tool was utilised [55]. The tool was reviewed to ensure all critical considerations for the economic model had been assessed and adequately addressed.

\section{Results}

\subsection{Base Case}

The results of the base-case analysis can be seen in Table 3 for the $2 \mathrm{~L}+$ cohort and Table 4 for the $3 \mathrm{~L}+$ cohort. In the case of the $2 \mathrm{~L}+$ cohort, the estimates showed an average discounted total QALY gain of 1.29. The total incremental costs were SEK 731,791, resulting in an ICER of 566,278 per QALY gained. The non-discounted survival gain amounted to 1.94 years. The results for the $3 \mathrm{~L}+$ cohort show an average discounted total QALY gain of 1.25 years. The total incremental costs were SEK 754,801, resulting in an ICER of SEK 603,934 per QALY gained. The non-discounted survival gain was 1.88 years. Since the clinical and 
Table 3 Base-case analysis for $2 \mathrm{~L}+$ cohort

\begin{tabular}{llll}
\hline & Lorlatinib & Pemetrexed & Difference \\
\hline QALYs & 1.6603 & 0.3680 & 1.2923 \\
PF-LYs & 1.4221 & 0.2030 & 1.2191 \\
LYs & 2.5044 & 0.5621 & 1.9423 \\
Drug costs (SEK) & 840,257 & 88,237 & 752,021 \\
Administration costs (SEK) & 0 & 23,029 & $-23,029$ \\
Disease management and moni- & 67,411 & 18,387 & 49,024 \\
$\quad$ toring costs (SEK) & & & \\
AE costs (SEK) & 543 & 814 & -271 \\
Subsequent therapy costs & 46,895 & 48,473 & -1578 \\
$\quad$ SEK) & & & \\
Terminal care costs (SEK) & 73,648 & 78,228 & -4580 \\
Total direct costs (SEK) & $1,028,753$ & 257,167 & 771,586 \\
Indirect costs (SEK) & $-46,989$ & -7193 & $-39,796$ \\
Total costs (SEK) & 981,764 & 249,974 & 731,791 \\
Cost per QALY (SEK) & & & $\mathbf{5 6 6 , 2 7 8}$ \\
Cost per LY (SEK) & & & $\mathbf{3 7 6 , 7 6 5}$ \\
\hline
\end{tabular}

$2 L+$ second line+, $A E$ adverse event, $L Y$ life year, $P F$ progression free, $Q A L Y$ quality-adjusted life year, $S E K$ Swedish krona

model data show patients treated with lorlatinib remain PF and live much longer than patients treated with pemetrexed, drug costs, disease management, and monitoring must be considered. These costs were partially offset by savings arising from the PF patients' ability to work.

\subsection{Sensitivity Analyses}

\subsubsection{Deterministic Sensitivity Analyses}

The results of the sensitivity analyses are shown in Tables 5 and 6, Fig. 2, and Supplement 2. The results are robust with respect to changes in parameter inputs that are clinically reasonable and they are most sensitive to changes in HRs. Moving from a societal perspective to a healthcare payer perspective increased the ICER to SEK 597,073 (2L+ cohort) and SEK 636,683 (3L+ cohort). Changing the time horizon from 20 to 10 years and excluding the indirect costs increased the ICER for the $2 \mathrm{~L}+$ and $3 \mathrm{~L}+$ cohorts to SEK 591,776 and SEK 632,578, respectively, reflecting the high mortality rate of the patient group. Only when HRs for PFS, OS, or PFS/OS combined were assumed to be much higher than the evidence suggests did the ICER increase substantially and approach the limit to what is normally considered to be an acceptable threshold in Sweden (SEK 988,000 for a high-severity disease) [28].

The following results were observed based on the TLV assumption analyses. In the base-case analysis where the OS HR was set at 0.425 , the estimates for the $2 \mathrm{~L}+$ cohort showed an average discounted total QALY gain of 0.847 years. The total incremental costs were SEK 620,220,
Table 4 Base-case analysis for 3L+ cohort

\begin{tabular}{llll}
\hline & Lorlatinib & Pemetrexed & Difference \\
\hline QALYs & 1.6083 & 0.3585 & 1.2498 \\
PF-LYs & 1.4700 & 0.2163 & 1.2537 \\
LYs & 2.4195 & 0.5431 & 1.8764 \\
Drug costs (SEK) & 868,129 & 89,101 & 779,029 \\
Administration costs (SEK) & 0 & 23,067 & $-23,067$ \\
Disease management and moni- & 63,483 & 17,359 & 46,124 \\
$\quad$ toring costs (SEK) & & & \\
AE costs (SEK) & 543 & 814 & -271 \\
Subsequent therapy costs & 47,099 & 48,741 & -1643 \\
$\quad$ SEK) & & & \\
Terminal care costs (SEK) & 73,834 & 78,274 & -4440 \\
Total direct costs (SEK) & $1,053,087$ & 257,356 & 795,731 \\
Indirect costs (SEK) & $-48,596$ & -7665 & $-40,930$ \\
Total costs (SEK) & $1,004,492$ & 249,691 & 754,801 \\
Cost per QALY (SEK) & & & $\mathbf{6 0 3 , 9 3 4}$ \\
Cost per LY (SEK) & & & $\mathbf{4 0 2 , 2 6 0}$ \\
\hline
\end{tabular}

$3 L+$ third-line+, $A E$ adverse event, $L Y$ life year, $P F$ progression free, $Q A L Y$ quality-adjusted life year, $S E K$ Swedish krona

resulting in an ICER of 732,138 per QALY gained. Varying the OS HR to 0.650 resulted in the QALY gain being 0.608 and the cost per QALY increasing to SEK 987,916. ${ }^{1}$ The major cost components, which made lorlatinib relatively more expensive, remained the same as in the base-case analysis (namely treatment and disease management costs).

\subsubsection{Probabilistic Sensitivity Analyses}

Probabilistic analysis showed an average QALY gain of 1.29 and incremental costs of SEK 742,181, resulting in a probabilistic ICER of 573,747 in the $2 \mathrm{~L}+$ cohort. In the $3 \mathrm{~L}+$ cohort, average QALYs gained were 1.25 with incremental costs of SEK 763,420, resulting in a probabilistic ICER of 610,918 . These results are consistent with the deterministic results. At a willingness-to-pay threshold of SEK 1,000,000, the probability that lorlatinib is cost-effective compared with chemotherapy is almost $100 \%$ in both the $2 \mathrm{~L}+$ and $3 \mathrm{~L}+$ cohorts (Supplement 5).

\section{Discussion}

The base-case analysis shows that the ICER of treating patients with lorlatinib instead of chemotherapy in $2 \mathrm{~L}+$ and 3L+ is SEK 566,278 and SEK 603,934, respectively,

\footnotetext{
1 The TLV evaluation was based on a PFS HR of 0.35 and the TLV calculated ICERs were SEK 729,798 (based on OS HR = 0.425) and SEK 983,628 (OS HR = 0.65). The HR has been updated after the TLV submission due to a correction of the baseline characteristics used in the MAIC analysis.
} 
Table 5 Sensitivity analyses for $2 \mathrm{~L}+$ cohort

\begin{tabular}{ll}
\hline Variable & Cost per QALY (SEK) \\
\hline Base case (as per Table 3) & 566,278 \\
Indirect costs excluded & 597,073 \\
And indirect costs excluded & \\
Utility first line according to SE tariff & 549,265 \\
Time horizon 10 years & 591,776 \\
RDI adjustment excluded & 596,015 \\
PFS log normal & 519,625 \\
PFS log logistic & 530,518 \\
OS Gompertz & 617,884 \\
PFS exponential & 443,210 \\
PFS exponential OS Gompertz & 485,402 \\
PFS HR $=0.362$, OS HR $=0.362$, as per & 710,030 \\
$\quad$ alternative MAIC & \\
OS HR $=0.5$ & 838,358 \\
OS HR $=0.5$ PFS HR $=0.5$ & 883,264 \\
\hline
\end{tabular}

$2 L+$ second line+, $H R$ hazard ratio, MAIC matching adjusted indirect comparison, $O S$ overall survival, $P F S$ progression-free survival, $Q A L Y$ quality-adjusted life year, $R D I$ relative dose intensity, $S E$ Sweden, SEK Swedish krona

Table 6 Sensitivity analyses for 3L+ cohort

\begin{tabular}{ll}
\hline Variables & Cost per QALY (SEK) \\
\hline Base case (as per Table 4) & 603,934 \\
Indirect costs excluded & 636,683 \\
And indirect costs excluded & \\
Utility first line according to SE tariff & 576,208 \\
Time horizon 10 years & 632,578 \\
RDI adjustment excluded & 635,578 \\
PFS log normal & 532,888 \\
PFS log logistic & 547,762 \\
OS Gompertz & 668,907 \\
PFS exponential & 468,005 \\
PFS exponential OS Gompertz & 547,963 \\
PFS HR $=0.362$, OS HR $=0.362$, as per & 758,692 \\
$\quad$ alternative MAIC & 896,403 \\
OS HR = 0.5 & 946,989 \\
OS HR $=0.5$ PFS HR $=0.5$ & \\
\hline
\end{tabular}

$3 L+$ third line+, $H R$ hazard ratio, MAIC matching adjusted indirect comparison, $O S$ overall survival, $P F S$ progression-free survival, $Q A L Y$ quality-adjusted life year, $R D I$ relative dose intensity, $S E$ Sweden, SEK Swedish krona

per QALY gained. Changing the analysis from a societal perspective to a healthcare payer perspective increases the ICER to SEK 597,073 (2L+ cohort) and SEK 636,683 (3L+ cohort). As always, the choice of parametric distribution has an impact on the results, but even when the worst fitting distributions are used the results are fairly stable. Although our analyses are subject to some uncertainties associated with an unanchored MAIC approach, these ICERs are well below the boundary of what is considered to be a cost-effective treatment in Sweden (approximately SEK 1,000,000 for a high-severity disease [28]).

The strength of our study is that we have taken data wherever possible from clinical trials, nationally available data sources, or previously published peer-reviewed studies. The key limitation of our study is that, like all modelling analyses, we have relied upon the use of assumptions and indirect comparisons, which inherently introduce an element of uncertainty into the estimates of cost-effectiveness. The analyses are therefore limited by the strong assumption needed for unanchored MAIC analyses that there are no prognostic factors or treatment effect modifiers in imbalance between the two populations, and the assumption that relative treatment effect is consistent irrespective of the number of prior treatments. Our sensitivity analyses used OS data from $\mathrm{Ou}$ et al., a retrospective analysis that assessed the clinical benefit of continuing crizotinib after initial disease progression (compared with patients who did not continue crizotinib after initial disease progression) in patients with advanced NSCLC [24]. The comparability of the study by Ou et al. [24] to the lorlatinib cohorts is limited by several factors, including that that study was retrospective and our analyses assumed that systemic therapy (after crizotinib) was suitable to represent the outcomes for chemotherapy; however, as the type of chemotherapy regimen was not collected by $\mathrm{Ou}$ et al., it is unclear exactly which treatments were received [24]. Finally, the number of patients receiving systemic therapy that could be utilised to form this comparison was relatively small (37 patients) [24]. However, as our SLR results suggested a lack of evidence for OS for this comparator, this publication (identified outside of the SLR as it did not fit the SLR criteria) was considered relevant. Nonetheless, the sensitivity analyses showed that the model results were robust to changes in the key parameters unless the HR values approached unrealistic levels. The results presented here are based on a Swedish societal perspective, and the generalisability of the findings may vary between countries with differing healthcare systems and costs. Our results can be related to two previous cost-effectiveness analyses of the ALK TKIs alectinib and ceritinib versus chemotherapy, both in a somewhat different treatment setting in the second and third line post-crizotinib, respectively. For alectinib, the TLV estimated the ICERs to be below SEK 900,000, and for ceritinib to be below SEK 930,000 [51, 52].

Previously, the only treatment option available to patients in Sweden who have failed on ALK TKIs has been chemotherapy, which is associated with a very poor prognosis. In a recent study of patients with advanced $A L K$-positive NSCLC refractory to one or more second-generation ALK TKIs who 


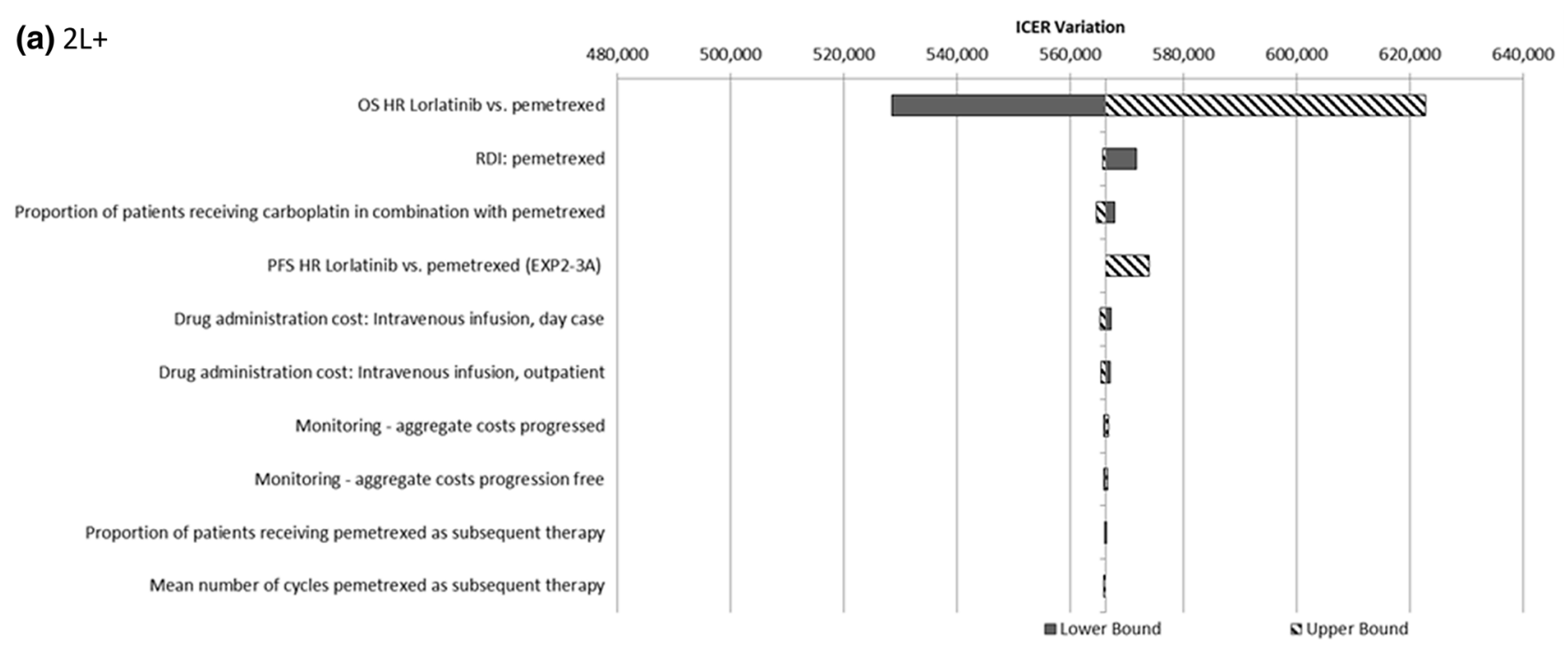

(b) $3 L+$
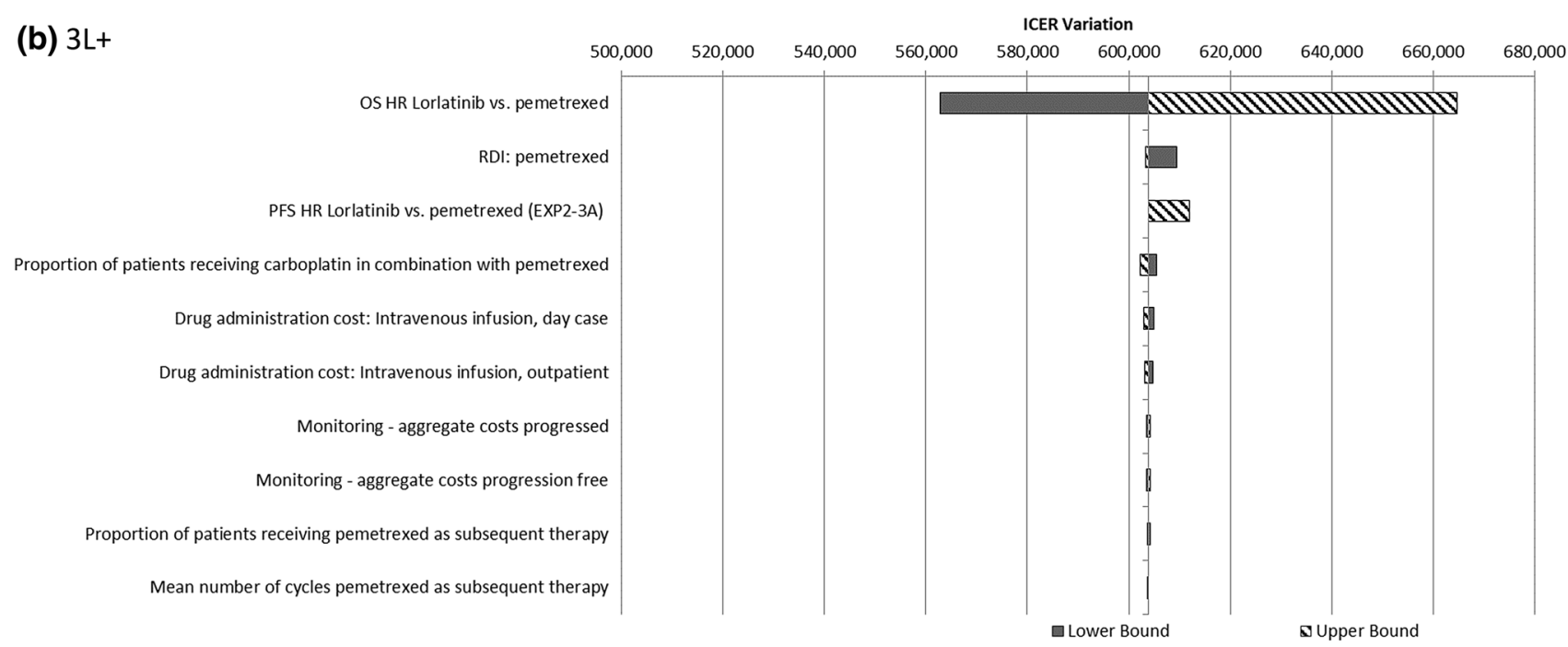

Fig. 2 Deterministic sensitivity analysis: Tornado diagrams. a $2 \mathrm{~L}+$; b $3 \mathrm{~L}+.2 L+$ second line+, $3 L+$ third line+, EXP expansion cohort, $H R$ hazard ratio, ICER cost-effectiveness ratio, $O S$ overall survival, $P F S$ progression-free survival, $R D I$ relative dose intensity

had received platinum/pemetrexed-based chemotherapy, the median duration of response was only 6.4 months $(95 \%$ CI 1.6 months to not reached) [56]. The median PFS for the entire cohort of patients receiving platinum/pemetrexedbased chemotherapy was 4.3 months (95\% CI 2.9-5.8) [56], whereas lorlatinib increases life expectancy substantially. Given the very high disease severity in this population, the ICER appears modest in relation to the commonly accepted thresholds in Sweden.

\section{Conclusions}

Our analysis, based on an unanchored MAIC, suggests that lorlatinib is a cost-effective treatment alternative for second- or third-line treatment of $A L K$-positive NSCLC, compared with chemotherapy. Although analyses such as ours are subject to some uncertainties, the ICERs are well below the willingness-to-pay threshold for what is considered to be a cost-effective treatment for a high-severity disease in Sweden.

Supplementary Information The online version contains supplementary material available at https://doi.org/10.1007/s40273-021-01015-8. 
Acknowledgements Editorial and medical writing support was provided by Keith Evans and Jade Drummond of inScience Communications, Springer Healthcare (Chester, UK), and Claire Lavin, $\mathrm{PhD}$, on behalf of CMC AFFINITY, McCann Health Medical Communications, with funding from Pfizer Inc.

\section{Declarations}

Funding This study was sponsored by Pfizer Inc. Medical writing support was funded by Pfizer.

Conflict of interest F. Nilsson is an employee of Pfizer Innovations $\mathrm{AB}$ and holds Pfizer Inc. stock and stock options. S.T. Asanin is an employee of Pfizer Innovations AB and holds Pfizer Inc. stock and stock options. E.T. Masters is an employee of Pfizer Inc. and holds Pfizer Inc. stock and stock options. L. Iadeluca is an employee of Pfizer Inc. and holds Pfizer shares, stock, and stock options. C. Almond, M. Cooper, and S. Smith are employees of BresMed. BresMed received consultancy fees from Pfizer Inc. for the development of the global cost-effectiveness model for lorlatinib and supporting statistical analyses. The authors did not receive direct payment as a result of this work outside of their normal salary payments.

Ethics approval Not applicable.

Consent to participate Not applicable.

\section{Availability of data and material Not applicable.}

Code availability Not applicable.

Authors' contributions FN, CA, MC, SS, and STA were involved in the conception and design of the study. All authors contributed to the analysis or interpretation of data for this work, contributed in drafting or revising it critically for important intellectual content, and approved the final version.

Open Access This article is licensed under a Creative Commons Attribution-NonCommercial 4.0 International License, which permits any non-commercial use, sharing, adaptation, distribution and reproduction in any medium or format, as long as you give appropriate credit to the original author(s) and the source, provide a link to the Creative Commons licence, and indicate if changes were made. The images or other third party material in this article are included in the article's Creative Commons licence, unless indicated otherwise in a credit line to the material. If material is not included in the article's Creative Commons licence and your intended use is not permitted by statutory regulation or exceeds the permitted use, you will need to obtain permission directly from the copyright holder. To view a copy of this licence, visit http://creativecommons.org/licenses/by-nc/4.0/.

\section{References}

1. Bray F, Ferlay J, Soerjomataram I, Siegel RL, Torre LA, Jemal A. Global cancer statistics 2018: GLOBOCAN estimates of incidence and mortality worldwide for 36 cancers in 185 countries. CA Cancer J Clin. 2018;68(6):394-424.

2. Hallberg B, Palmer RH. ALK and NSCLC: Targeted therapy with ALK inhibitors. F1000 Med Rep. 2011;3:21.

3. Ke L, Xu M, Jiang X, Sun X. Epidermal growth factor receptor (EGFR) mutations and anaplastic lymphoma kinase/oncogene or C-Ros oncogene 1 (ALK/ROS1) fusions inflict non-small cell lung cancer (NSCLC) female patients older than 60 years of age. Med Sci Monit. 2018;24:9364-9.

4. Cancer.Net. Lung cancer-non-small cell: statistics. 2020 [cited 2020 July 28]; https://www.cancer.net/cancer-types/lung-cancernon-small-cell/statistics.

5. Cancerfonden. Cancerfondsrapporten 2018 [cited 2020 July 28]; https://static-files.cancerfonden.se/Cancerfondsrapporten2018_ webb_(2)_1521607903.pdf.

6. Regionalt Cancercentrum. Lungcancer Nationellt vårdprogram. 2020 [cited 2020 July 28]; https://www.cancercentrum.se/globa lassets/cancerdiagnoser/lunga-och-lungsack/vardprogram/natio nellt-vardprogram-lungcancer.pdf.

7. Planchard D, Popat S, Kerr K, Novello S, Smit EF, Faivre-Finn C, et al. Metastatic non-small cell lung cancer: ESMO Clinical Practice Guidelines for diagnosis, treatment and follow-up. Ann Oncol. 2019;30(5):863-70.

8. Addeo A, Tabbo F, Robinson T, Buffoni L, Novello S. Precision medicine in ALK rearranged NSCLC: a rapidly evolving scenario. Crit Rev Oncol Hematol. 2018;122:150-6.

9. Auliac JB, Monnet I, Dubos-Arvis C, Chiappa AM, Baize N, Bota $\mathrm{S}$, et al. Non-small-cell lung cancer (NSCLC) harboring $A L K$ translocations: clinical characteristics and management in a real-life setting: a French retrospective analysis (GFPC 02-14 Study). Targ Oncol. 2017;12(6):833-8.

10. Casaluce F, Sgambato A, Maione P, Rossi A, Ferrara C, Napolitano A, et al. ALK inhibitors: a new targeted therapy in the treatment of advanced NSCLC. Targ Oncol. 2013;8(1):55-67.

11. Recondo G, Facchinetti F, Olaussen KA, Besse B, Friboulet L. Making the first move in $E G F R$-driven or $A L K$-driven NSCLC: first-generation or next-generation TKI? Nat Rev Clin Oncol. 2018;15(11):694-708.

12. Akamine T, Toyokawa G, Tagawa T, Seto T. Spotlight on lorlatinib and its potential in the treatment of NSCLC: the evidence to date. Onco Targ Ther. 2018;11:5093-101.

13. Basit S, Ashraf Z, Lee K, Latif M. First macrocyclic 3rd-generation ALK inhibitor for treatment of ALK/ROS1 cancer: clinical and designing strategy update of lorlatinib. Eur J Med Chem. 2017;134:348-56.

14. Lai Y, Kacal M, Kanony M, Stukan I, Jatta K, Kis L, et al. miR100-5p confers resistance to ALK tyrosine kinase inhibitors Crizotinib and Lorlatinib in EML4-ALK positive NSCLC. Biochem Biophys Res Commun. 2019;511(2):260-5.

15. Abbvie Inc. Niaspan (niacin extended-release): U.S. prescribing information. 2018.

16. Recondo G, Mezquita L, Facchinetti F, Planchard D, Gazzah A, Bigot L, et al. Diverse resistance mechanisms to the third-generation ALK inhibitor lorlatinib in ALK-rearranged lung cancer. Clin Cancer Res. 2019.

17. Solomon BJ, Besse B, Bauer TM, Felip E, Soo RA, Camidge $\mathrm{DR}$, et al. Lorlatinib in patients with $A L K$-positive non-small-cell lung cancer: results from a global phase 2 study. Lancet Oncol. 2018;19(12):1654-67.

18. European Medicines Agency. Assessment Report: Lorviqua. 2019.

19. European Medicines Agency. Lorviqua (lorlatinib). 2020 [cited 2021 January 17]; https://www.ema.europa.eu/en/medicines/ human/EPAR/lorviqua.

20. Gallacher D, Auguste P, Royle P, Mistry H, Armoiry X. A systematic review of economic evaluations assessing the cost-effectiveness of licensed drugs used for previously treated epidermal growth factor receptor (EGFR) and anaplastic lymphoma kinase (ALK) negative advanced/metastatic non-small cell lung cancer. Clin Drug Investig. 2019;39(12):1153-74.

21. Woods B, Sideris E, Palmer S, Latimer N, Soares M. NICE DSU Technical support document 19. Partitioned survival analysis for decision modelling in health care: a critical review. 2017 [cited 2021 January 12]; http://www.nicedsu.org.uk. 
22. Shaw AT, Felip E, Bauer TM, Besse B, Navarro A, Postel-Vinay S, et al. Lorlatinib in non-small-cell lung cancer with $A L K$ or $R O S 1$ rearrangement: an international, multicentre, open-label, singlearm first-in-man phase 1 trial. Lancet Oncol. 2017;18(12):1590-9.

23. Novello S, Mazieres J, Oh IJ, de Castro J, Migliorino MR, Helland A, et al. Alectinib versus chemotherapy in crizotinib-pretreated anaplastic lymphoma kinase (ALK)-positive non-small-cell lung cancer: results from the phase III ALUR study. Ann Oncol. 2018;29(6):1409-16.

24. Ou S-HI, Jänne PA, Bartlett CH, Tang Y, Kim D-W, Otterson GA, et al. Clinical benefit of continuing ALK inhibition with crizotinib beyond initial disease progression in patients with advanced $A L K$ positive NSCLC. Ann Oncol. 2014;25(2):415-22.

25. Pharmaceutical Benefits Board. General guidelines for economic evaluations from the Pharmaceutical Benefits Board (LFNAR 2003:2). 2003 [cited 2020 July 28]; https://www.tlv.se/download/ 18.2e53241415e842ce95514e9/1510316396792/Guidelines-foreconomic-evaluations-LFNAR-2003-2.pdf.

26. Tandvårds-och läkemedelsförmånsverket. Sökanda. Saken. Beslut. Ansökan inom läkemedelsförmånerna. Lorviqua. 2019 [cited 2020 July 28]; https://www.tlv.se/download/18.97e9b7116d67851 7ccafb3d/1569913536745/bes190926_lorviqua.pdf.

27. Tandvårds-och läkemedelsförmånsverket. Ändring i Tandvårdsoch läkemedelsförmånsverkets allmänna råd (TLVAR 2003:2) om ekonomiska utvärderingar. 2017 [cited 2020 July 28]; https:// www.tlv.se/download/18.467926b615d084471ac3230c/15103 16374332/TLVAR_2017_1.pdf.

28. Svensson M, Nilsson FOL, Arnberg K. Reimbursement decisions for pharmaceuticals in Sweden: the impact of disease severity and cost effectiveness. Pharmacoeconomics. 2015;33(11):1229-36.

29. Latimer N. NICE decision support unit technical support document 14: survival analysis for economic evaluations alongside clinical trials-extrapolation with patient-level data. 2011

30. Smith S, Albuquerque de Almeida F, Ines M, Iadeluca L, Cooper M. Matching-adjusted indirect treatment comparisons of the effect of lorlatinib versus chemotherapy on overall survival and progression-free survival for patients with second-line or later anaplastic lymphoma kinase-positive non-small-cell lung cancer. Presented at the International Society for Pharmacoeconomics and Outcomes Research-23rd Annual European Congress. 16-19 November 2020

31. Signorovitch JE, Sikirica V, Erder MH, Xie J, Lu M, Hodgkins PS, et al. Matching-adjusted indirect comparisons: a new tool for timely comparative effectiveness research. Value Health. 2012;15(6):940-7.

32. Shaw AT, Kim TM, Crinò L, Gridelli C, Kiura K, Liu G, et al. Ceritinib versus chemotherapy in patients with $A L K$-rearranged non-small-cell lung cancer previously given chemotherapy and crizotinib (ASCEND-5): a randomised, controlled, open-label, phase 3 trial. Lancet Oncol. 2017;18(7):874-86.

33. National Institute for Health and Care Excellence. Crizotinib for treating ROS1-positive advanced non-small-cell lung cancer. 2018.

34. Statistical database. 2020 [cited 2020 September 14]; http://www. statistikdatabasen.scb.se/pxweb/sv/ssd/.

35. Aaronson NK, Ahmedzai S, Bergman B, Bullinger M, Cull A, Duez NJ, et al. The European Organization for Research and Treatment of Cancer QLQ-C30: a quality-of-life instrument for use in international clinical trials in oncology. J Natl Cancer Inst. 1993;85(5):365-76.

36. Fayers P, Bottomley A, EORTC Quality of Life Group, Quality of Life Unit. Quality of life research within the EORTCthe EORTC QLQ-C30. European Organisation for Research and Treatment of Cancer. Eur J Cancer. 2002;38(Suppl 4):S125-33.

37. Bergman B, Aaronson NK, Ahmedzai S, Kaasa S, Sullivan M. The EORTC QLQ-LC13: a modular supplement to the EORTC
Core Quality of Life Questionnaire (QLQ-C30) for use in lung cancer clinical trials. EORTC Study Group on Quality of Life. Eur J Cancer. 1994;30a(5):635-42.

38. Bottomley A, Efficace F, Thomas R, Vanvoorden V, Ahmedzai SH. Health-related quality of life in non-small-cell lung cancer: methodologic issues in randomized controlled trials. J Clin Oncol. 2003;21(15):2982-92.

39. Longworth L, Yang Y, Young T, Mulhern B, Hernández Alava M, Mukuria C, et al. Use of generic and condition-specific measures of health-related quality of life in NICE decision-making: a systematic review, statistical modelling and survey. Health Technol Assess. 2014;18(9):1-224.

40. Dolan P. Modeling valuations for EuroQol health states. Med Care. 1997;35(11):1095-108.

41. Burström K, Sun S, Gerdtham U-G, Henriksson M, Johannesson M, Levin LA, et al. Swedish experience-based value sets for EQ-5D health states. Qual Life Res. 2014;23(2):431-42.

42. Longworth L, Rowen D. NICE Decision Support Unit Technical Support Documents. NICE DSU technical support document 10: the use of mapping methods to estimate health state utility values. London: National Institute for Health and Care Excellence (NICE); 2011.

43. Zhou Z, Zhang J, Fan L, Zhang C, Xie J. Cost-effectiveness of ceritinib in the treatment of previously treated anaplastic lymphoma kinase-positive (Alk+) non-small cell lung cancer in the United Kingdom. Value Health. 2015;18(7):PA455-56.

44. National Institute for Health and Care Excellence. Crizotinib for previously treated anaplastic lymphoma kinase-positive advanced non-small-cell lung cancer (TA422). 2016 December 21 [cited 2020 September 14]; https://www.nice.org.uk/guidance/ta422.

45. Blom EF, Haaf KT, de Koning HJ. Systematic review and metaanalysis of community- and choice-based health state utility values for lung cancer. Pharmacoeconomics. 2020;38(11):1187-200.

46. Burstrom K, Johannesson M, Diderichsen F. Swedish population health-related quality of life results using the EQ-5D. Qual Life Res. 2001;10(7):621-35.

47. Sök i databasen. [cited 2021 January 12]; https://www.tlv.se/ beslut/sok-i-databasen.html?tab=3.

48. Solomon BJ, Mok T, Kim D-W, Wu Y-L, Nakagawa K, Mekhail $\mathrm{T}$, et al. First-line crizotinib versus chemotherapy in $A L K$-positive lung cancer. N Engl J Med. 2014;371(23):2167-77.

49. Tandvårds- och läkemedelsförmånsverket. Ansökan inom läkemedelsförmånerna. Underlag för beslut. Lorviqua. 2019 [cited 2021 February 2]; https://www.tlv.se/download/18.77dd84fe16d6748 c8f6ef3aa/1570096873352/bes190926_underlag_lorviqua.pdf.

50. Södra sjukvårdsregionen. Regionala priser och ersättningar för Södra sjukvårdsregionen 2019 [cited 2020 July 28]; https://sodra sjukvardsregionen.se/download/regionala-priser-och-ersattning ar-for-sodra-sjukvardsregionen-2019/.

51. Tandvårds- och läkemedelsförmånsverket. Beslut. Ansökan inom läkemedelsförmånerna. Alecensa. 2017 [cited 2021 February 2]; https://www.tlv.se/download/18.22f5c35f16020eae8d84 158/1512392896311/bes171124_alecensa.pdf_;!!N96JrnIq8I fO5w!xZIpon4wHkZQP47yeeXYoGaErm31x3uTebAku6Ld9u6_ uT6-hK3ndUPO0jg54DANOlcZD_etq1e4omxPBrk\$.

52. Tandvårds- och läkemedelsförmånsverket. Beslut. Ansökan inom läkemedelsförmånerna. Zykadia. 2015 [cited 2021 February 2]; https://www.tlv.se/download/18.467926b615d084471ac3 0427/1510316361729/Bes151210_zykadia.pdf_;!!N96JrnIq8I fO5w!xZIpon4wHkZQP47yeeXYoGaErm31x3uTebAku6Ld9u6_ uT6-hK3ndUPO0jg54DANOlcZD_etq1e4luX4e_c\$.

53. Skatteverket. Arbetsgivaravgifter. 2020 [cited 2020 July 28]; https://www.skatteverket.se/foretagochorganisationer/arbetsgiva re/arbetsgivaravgifterochskatteavdrag/arbetsgivaravgifter.4.233f9 1f71260075abe8800020817.html. 
54. Statistikmyndigheten SCB. Average monthly salary, SEK by sector, occupation (SSYK 2012), sex, level of education and year. 2019 [cited 2020 July 28]; http://www.statistikdatabasen.scb.se/ pxweb/en/ssd/START_AM_AM0110/.

55. Vemer P, Corro Ramos I, van Voorn GA, Al MJ, Feenstra TL. AdViSHE: a validation-assessment tool of health-economic models for decision makers and model users. Pharmacoeconomics. 2016;34(4):349-61.
56. Lin JJ, Schoenfeld AJ, Zhu VW, Yeap BY, Chin E, Rooney M, et al. Efficacy of platinum/pemetrexed combination chemotherapy in $A L K$-positive non-small cell lung cancer refractory to secondgeneration ALK inhibitors. J Thorac Oncol. 2020;15(2):258-65. 